ISSN: 0213-3563

http://dx.doi.org/10.14201/azafea2019211131

\title{
REFLEXIONES SOBRE ANTROPOCENO Y COLAPSO
}

\section{Reflections on Anthropocene and collapse}

Luciano EsPinosa Rubio

Titular de Filosofía en la Universidad de Salamanca

Recibido: 21 de marzo de 2019

Aceptado: 19 de abril de 2019

\section{RESUMEN}

Vivimos en el Antropoceno, tomado en sentido amplio, donde lo geológico y lo histórico convergen porque la acción humana lo hace posible. El cambio climático y la explotación global de recursos naturales y de las estructuras capitalistas conducen al género humano hacia el colapso de la civilización tal como la conocemos. Hay algunas relaciones importantes entre Antropoceno y colapso que muestran a la vez el poder y la impotencia de la humanidad.

Palabras clave: Antropoceno, colapso, cambio climático, violencia, complejidad.

\begin{abstract}
We are living in the Anthropocene, in its broad sense, where the geological and the historical converge since human action makes it possible. Climate Change and the global exploitation of natural resources and the capitalism structures lead mankind towards the collapse of civilization as we know it. There are some important relations between Anthropocene and Collapse that show simultaneously the power as well as the impotence of humanity.
\end{abstract}

Key words: Anthropocene, Collapse, Climate Change, Violence, Complexity.

\section{Sentido y PROPÓSITO}

Nuestra época se define por una complejidad extraordinaria, que es mucho más que mera complicación: demasiadas variables y nexos, niveles y facetas, 
incógnitas e intereses..., según retroacciones impredecibles dentro de sistemas no lineales, que desbordan las pocas ecuaciones y organizaciones que hay para procesarlos. La historia, fraguada por unos flujos múltiples y ajenos a la idea de progreso, ha desembocado en una acelerada acumulación de bifurcaciones o saltos cualitativos, necesidades y aporías que no dejan apenas tiempo para reaccionar. $\mathrm{O}$, si se prefiere, en una policrisis de civilización y de supervivencia para la especie humana y otras muchas, llena de peligrosas contingencias eco-políticas y con unos plazos más que ajustados para intervenir. Hace falta bastante más que útiles algoritmos para frenar la entropía y comprimir esa densidad inmanejable, sin caer en otro espejismo reduccionista. Lejos de la resignación apocalíptica, lo que aquí proponemos es un breve examen que colabore a una mejor ilustración y al debate sobre la gran "batalla ideológica de nuestro tiempo", pues el cambio climático cuestiona casi todo el tipo de vida uncido al dios mercado, lo que incluye ideales antropológicos y morales ligados a la ganancia por encima de todo (Klein, 2015: 60ss., 87). Digamos que no somos máquinas egoístas y codiciosas, como se quiere hacer creer, pero sí bastante manipulables e inconscientes.

Además de los importantísimos cambios geopolíticos, económicos y tecnológicos (baste recordar la guerra fría y comercial en ciernes, la financiarización y el endeudamiento masivos, la crisis del sistema democrático, los varios tipos de terrorismo o el impacto de las tecnologías NBIC), desde un punto de vista ambiental hay que lidiar con una red enmarañada de vínculos y ciclos saturados de interferencias, de procesos emergentes y de azares, en el seno de una propia y peculiar planetarización: sea por un cruce de escalas espacio-temporales inédito (efectos de muy largo alcance, lazos global-local, distribución geográfica del cambio climático); o por los flujos de materia y energía, tan gigantescos e interdependientes que no sólo sufren una extrema vulnerabilidad (Spier, 2011: 388ss.), sino que parecen ingobernables para acompasar los metabolismos naturales y artificiales. Si la energía es una especie de moneda o comodín cósmico y en buena medida también humano, hay un serio riesgo de que los sistemas artificiales que ha permitido erigir (junto a la información) acaben muriendo de éxito, esto es, por exceso de complejidad, entre otras cosas porque aquélla deja de ser abundante y barata. Por lo demás, una descompensación grave o un cortocircuito en algún nodo del entramado puede tener consecuencias muy dañinas.

Acaso el rasgo básico y paradójico del Antropoceno es que los humanos han sido tan poderosos como para cambiar hasta tal punto el entorno... que se les ha ido el control de las manos. El sibilino apotegma baconiano de 
obedecer a la naturaleza para dominarla ha saltado por los aires, al no reconocer un mínimo equilibrio y algo tan obvio como que todo es finito. Qué potencia soberana tan impotente cuando la soberbia ciega y la cantidad (mal calibrada además) se impone definitivamente a la calidad en todos los órdenes de la vida, o cuando las inercias socio-económicas apenas encubren la anomia y la huida a ninguna parte. Quizá por eso el ambiguo mantra del desarrollo sostenible deja paso ahora a términos de nuevo cuño como adaptación y mitigación de los desastres, siempre desde el refinamiento tecnológico del sistema de producción y consumo, o, en el mejor caso, con decrecimiento. Ni siquiera los ricos think tanks conservadores (Heritage, Cato, Heartland...), entre otros insidiosos "mercaderes de la duda" -con estrategias semejantes que las tabacaleras- respecto a las crisis ambientales (Oreskes y Conway, 2010), pueden parar la toma de conciencia y ciertas reformas paliativas, aunque sean harto insuficientes.

Sin embargo, la falta de gobernanza global es un fenómeno generalizado que agrava los males anteriores, una vez que los relatos y los modelos de vida quiebran y/o se multiplican, lo que complementa la vigente fragmentación del poder (Naím, 2015) en todos los sentidos y ámbitos (internacionales, institucionales, corporativos, agentes informales, etc.), de manera que no hay un monopolio tiránico, pero tampoco coordinación bastante para actuar. A lo que acompaña la secuela de fracturas sociales y culturales (populismos, xenofobia, nacionalismo, competencia feroz ante la escasez de bienes, recursos y empleos...). El resultado es que a la sociedad de los peligros globales (que definió Ulrich Beck), le sucede la amenaza cierta de un colapso estructural de proporciones incalculables que tal vez incluya varios de esos peligros. $Y$ todo ello deja expedito el camino a que la violencia se convierta en la forma privilegiada de la racionalidad instrumental para sobrevivir en ese nuevo entramado global, sin que siquiera se cuente con una teoría socio-política de las catástrofes, capaz de afrontar los lazos explosivos entre ecología, crecimiento, geopolítica y migraciones (Welzer, 2010: 14ss., 39, 53, 76ss., 122). La humanidad, en fin, no está preparada para tal grado de complejidad destructiva, preñada de riesgos inauditos.

\subsection{A vueltas con el Antropoceno}

El concepto se ha puesto de moda con toda razón desde que lo utilizaron por primera vez Crutzen y Stoermer (2000) para referirse a la era geológica 
posterior al Holoceno marcada por la acción humana a escala planetaria (al menos desde el siglo XX), aunque el debate en términos técnicos estratigráficos todavía está abierto (Rull, 2018). Con independencia de ello, el vocablo sirve como herramienta de análisis del presente, sometido a diferentes lecturas e interpretaciones ideológicas, de las que se hablará luego. De momento, conviene delimitarlo con unos datos asombrosos: los humanos han multiplicado por siete su población desde el año 1800, mientras que la economía se ha multiplicado por cincuenta y el uso de energía por cuarenta, lo que los ha llevado a ocupar y/o afectar de una u otra forma el $80 \%$ de la superficie terrestre. Las huellas principales que ello deja son la persistente radiación atómica; la alteración del importantísimo ciclo del hidrógeno; la contaminación masiva del aire, del mar y del subsuelo; la creación de unas 75.000 sustancias químicas artificiales, cuyos efectos y mezclas son desconocidos; la emisión de gases de efecto invernadero (GEI), que aun si se detuviera ahora mismo seguirían actuando unos 300 años en la atmósfera; la sexta gran extinción de seres vivos, que altera múltiples ecosistemas; el control de la inmensa mayoría de la biomasa terrestre (menos del 3\% del total son animales silvestres) por una especie como la nuestra que supone el $0.04 \%$ del total; la invasión asfixiante del plástico y del cemento -por ser gráficos- frente a una naturaleza virgen casi desaparecida... En fin, toda una serie de distorsiones profundas de los ciclos naturales de gran alcance espacio-temporal, que además se retroalimentan en clave sistémica.

Cualquier definición es cultural y ambivalente, claro, pero el sentido del Antropoceno se enriquece al relacionarla con la noción Sistema Tierra: el planeta se comporta como un sistema único y autorregulado, constituido por la articulación de aspectos geológicos, físicos, químicos, biológicos y humanos. Así lo certificó la Declaración de Ámsterdam de 2001, suscrita por más de 100 países y desarrollada a través de grandes programas de investigación dentro de la Asociación de la Ciencia del Sistema Tierra, centrados en sus dinámicas no lineales que operan según umbrales críticos, lo que a su vez demanda la realización de estudios inter y transdisciplinares (Ayestarán, 2009: 72s, 78). Podría decirse que la acción humana lo modifica hasta configurar otra realidad histórico-sistémica, estudiada con nuevos instrumentos teóricos y prácticos. Tal es el objeto inclusivo del que se ocupan diferentes instituciones como, por ejemplo, LDEO y Earth Institute de la Universidad de Columbia, el CIESIN de Nueva York, Momentum Institut de París o el ICTA de la UAB. Lo que importa destacar, entonces, es el cambio de paradigma -para estar a la altura de los tiempos- que se adivina en torno a las 
teorías de la complejidad y la ecología, tomadas ambas en sentido amplio y muy trabado.

También se puede hablar en sentido filosófico de la integración de la vida en una eco-bio-tecno-noos-fera cada vez más tupida, y referirse en especial al impacto tecnológico del último siglo como catalizador y soporte de esa transversalidad de las conexiones (Espinosa, 2007). Los análisis no deben hacer que se pierda de vista el enfoque sintético donde encajan y cobran sentido. Por otro lado, es preciso entender el metabolismo común a lo natural y lo artificial para elaborar una política de gran aliento, lo que según muchos debería tener un sesgo reformador y liberal, sin implicar un cambio grande en el estilo de vida que la gente no aceptaría, si es que se quiere ser realista y eficaz (Arias Maldonado, 2018). Sin duda conviene ser prudentes, pero no renunciar a los cambios ambiciosos, pues el problema es que dicho sistema antropocénico se desestabiliza cada vez más y no parece que sirva un parcheo. Y eso, además, no debería tomarse sólo en clave pragmática o como un resultado histórico inevitable y mucho menos neutral, sino que resulta indesligable de la crisis ecológica global a todos los efectos, lo que lleva aparejada unas dinámicas de injusticia, conflicto y desigualdad disparadas (Hamilton et al., 2015). En vez de entrar en el falso debate sobre si hay o no una alarma exagerada sobre los centenares de casos donde hay violencia de origen ambiental, basta consultar los registros anuales que recoge y actualiza el Environmental Justice Atlas (UAB) a nivel planetario.

Por lo que se refiere al socorrido posibilismo cifrado en la llamada economía verde, permítase recordar lo evidente: que monetariza y mercantiliza la naturaleza como siempre, e incluso amplía la colusión entre capital natural y negocio, más allá del marketing y de pequeños avances. El caso de la compraventa de $\mathrm{CO}_{2}$ revela, por otra parte, cómo los mecanismos de mercado usados para limitar las emisiones se convierten en otro motivo especulativo que mueve alrededor del cuarto de billón de dólares al año. Con el añadido de la reducción habitual del cambio climático al carbono, lo que suele dejar fuera del debate otros asuntos relativos a las causas en vez de a los efectos, como la producción más contaminante (fracking, arenas bituminosas...) de combustibles fósiles, o la reivindicación esencial de la denominada justicia climática, o la huida hacia adelante de una sociedad de consumo apalancada en la obsolescencia programada (Moreno et al. 2015). Temas que no son abordados de frente en ninguna cumbre climática internacional, entre otras cosas porque nunca se cuestionan las actividades humanas más rentables ni las consecuencias radicales de esos procesos. Y es sabido que los combustibles fósiles 
reciben casi tres veces más subvenciones públicas (unos 600.000 millones de dólares) que las energías limpias, según cifras oficiales. Por último, en otro orden de cosas, conviene recordar un hecho revelador de cómo funciona el mercado en relación a estos asuntos, cuando de verdad tiene interés en algo: desde hace años hay una compra masiva a bajo precio de tierras fértiles, sobre todo en África, por parte de países asiáticos, y de reservas de agua dulce, sobre todo en Sudamérica, por parte de grandes corporaciones, lo que ya dice bastante de la situación y de los movimientos estratégicos en curso.

Tampoco debe olvidarse -para entender hasta dónde llega el reformismo capitalista- que los poderes políticos y económicos han impedido la puesta en marcha de tasas tan módicas como la ya célebre que propuso hace lustros J. Hansen al carbono u otras (como la Tobin) al movimiento de capitales especulativos. Y esto ocurre mientras hay unos 50 paraísos fiscales que ocultan entre 10 y 20 billones de dólares para no tributar, a la vez que el fraude fiscal de las grandes multinacionales supera el medio billón de dólares al año (Tax Justice Network). Con estas cifras sobre la mesa, la cruel ironía es que se dice a los ciudadanos que asuman una precariedad permanente y que el estado del bienestar (en los pocos lugares donde existe) tiene que reducirse por el déficit fiscal. Por no hablar de que el creciente gasto militar anual es muchísimo más grande que lo que costaría satisfacer los 17 Objetivos de Desarrollo Sostenible (ODS) lanzados por la ONU. Para terminar este breve recordatorio hay que pensar que la última gran estafa, mal llamada recesión, ha duplicado la desigualdad a escala mundial, amén de dejar claras cuáles son las prioridades y hasta dónde llega la traición de las élites respecto a la gran mayoría de la gente (Riemen, 2018). No hace falta insistir, en fin, sobre la hipocresía de ciertas promesas y esperanzas.

El miedo y el resentimiento de muchos ciudadanos son comprensibles, pero no por eso dejan de ser torpes y destructivos, especialmente cuando se vuelca sobre los desfavorecidos en lugar de enfrentarse a los poderosos, aunque también haya sido manipulado por toda clase de populistas y medios de desinformación. En cualquier caso, a nadie puede extrañar la desafección hacia la democracia y las múltiples fracturas que recorren la sociedad, una vez que se ha roto en buena medida el contrato social vigente, en el que por cierto ya se había degradado la fundamental alianza histórica entre igualdad y libertad hasta convertirlas en antagonistas (Rosanvallon, 2012: 11, 14ss., 18ss.). Y este divorcio es lo peor. Además, la conocida hegemonía de lo económico sobre lo político desde los años 80 es palmaria y difícil de revertir, suponiendo que no sean hermanas siamesas y el problema sea aún más profundo. 
Pero ése es un tema que merecería su propio desarrollo. Por resumir con una fórmula lo que ahora nos atañe, la voracidad de este capitalismo omnívoro no tiene límites y el mercado se convierte realmente en aquello que está más allá del bien y del mal en sentido estructural (Coetzee, 2007: 111). El fetichismo inherente es de tal magnitud que pasa desapercibido, pero hay otra vertiente del pensamiento mágico: la tecnolatría irracional como solucionadora de todos los problemas, en especial en su vertiente informática (aparte de que no sale gratis, pues sólo las redes suponen un gasto del $4 \%$ de la energía total y subiendo a marchas forzadas).

Antes de aportar nuevos elementos de análisis, importa dejar sentada una posición previa: se ha dicho con razón que dada la magnitud y urgencia del problema ambiental, sobre todo el cambio climático, no cabe adoptar la falsa posición de un término medio basado en dar pasos graduales e indoloros; y que ni siquiera bastan las meras modificaciones legales y culturales en torno a la conciencia ambiental, toda vez que lo que está en juego es una tremenda lucha de poder de cuyo resultado material depende en buena parte la gravedad del probable colapso; lo que incluye la denuncia de ciertas políticas criminales (comerciales, de seguridad nacional...) que ya dan por perdidos a sectores enteros de la población mundial (Klein, 2015: 38, 55ss., 83ss., 555ss., 565,33 ss.). No sirve de nada contemporizar ni asustarse, por más difícil que sea remover los obstáculos que avalan la inercia e impiden la transformación mínima necesaria, a su vez muy difícil de concretar. Aun así, el cambio es el eje del verdadero realismo ante una situación que amenaza con ser de vida o muerte.

Acaso resulte más pertinente hablar de capitaloceno, dado que no es la humanidad en sentido genérico la responsable de esta situación, sino determinadas estructuras con agentes bien diferenciados que dirigen y se benefician del modelo imperante (Moore, 2015). Luego la culpa de los desequilibrios generados por la acción humana y los sacrificios para corregirlos no pueden ser iguales para todos, aunque la gran mayoría de ciudadanos viva en un régimen de producción y consumo capitalista y se muestre reacia a cambiar su estilo de vida. Sobre todo a la vista de que el $10 \%$ de la población mundial, la más rica, produce más de la mitad de las emisiones de $\mathrm{CO}_{2}$, mientras que el $50 \%$ de los habitantes del planeta sólo genera el 10\% de éstas, asimetría que se multiplica al constatar que el $1 \%$ más rico produce 30 veces más gases que esa mitad de la población más pobre; a lo que se añade que durante la historia han sido 90 corporaciones las que han emitido alrededor del 55\% de los GEI o que, por ejemplo, el ejército de EE. UU. consume en el presente siglo más 
petróleo que ninguna otra institución (Cano, 2018: 3). De forma que a la lectura más o menos neutra y en términos abstractos (que son los de la ciencia), le deben seguir los rasgos éticos y políticos. Dicho con otras palabras, hace falta una ecología política y una ética ambiental mucho más potentes.

$\mathrm{Y}$ es que, como en tantas cosas de nuestro tiempo, hay diferentes relatos a considerar respecto al Antropoceno, bien resumidos por A. Herrero (2017: 4ss.): el primero es el relato naturalista del poder de la ciencia, según el cual los humanos son desde hace tiempo el motor de la historia planetaria y deben encontrar formas eficaces de seguir adelante, dentro de un esquema general de progreso que corrija y mejore cuanto sea necesario; el segundo es el ecopragmatismo que constata la muerte de la naturaleza, que al fin y al cabo siempre ha sido un constructo cultural mediado tecnológicamente, de modo que hay que continuar con el proceso de artificialización creciente, asumiendo riesgos e incertidumbres sin grandes reparos; el tercer relato es el ecocatastrofista, donde el antropoceno se interpreta como la culminación de una larga historia de desatinos e injusticias que abocan al colapso, por lo que se deberían hacer cambios de fondo en el sistema globalizado de producción y consumo, empezando por el decrecimiento y terminando por la autogestión local; el cuarto es el ecomarxismo, para el cual son las diversas contradicciones del capitalismo y sus formas de explotación y expolio las que han determinado el presente, sin que se puedan afrontar los problemas hasta no haberlo dejado atrás; y el último relato principal es ecofeminista, para el que denunciar el patriarcado anexo a los errores mencionados, a su vez en el seno de los dualismos de la modernidad (naturaleza-humanos...), permite comprender mejor lo ocurrido y oponer una ética del cuidado y la compasión, así como una justicia ambiental que incluya otras especies.

Las actitudes y los diagnósticos difieren, pero todos reconocen la importancia del momento y la necesidad de tener en cuenta nuevas variables. Unos parecen apostar por el reformismo y otros por transformaciones drásticas y urgentes; los primeros insisten en perfeccionar los mecanismos civilizatorios vigentes y los segundos en virar tanto como se pueda el rumbo de la humanidad. Es muy arduo asumir de una vez que los riesgos son gravísimos y superar la célebre disonancia cognitiva (entre ideas, creencias, temores y deseos enfrentados) que a tantos arrastra, pues la inconsciencia, la comodidad y el temor aún prevalecen. La conocida distinción que cabría aplicar entre apocalípticos e integrados se hace aún más difícil ante la necesidad de trascender las dicotomías entre cuestiones de hecho y de valor, o entre agencia libre y heteronomía, pues son cosas que requieren gran afinamiento y prudencia dentro 
del paradigma ecológico de las múltiples relaciones. Son tantos los conflictos y cruces de intereses, prejuicios, peligros y fines que conviene reforzar los argumentos en favor del cambio con nuevos datos e implicaciones, haciendo ver que lo que está en juego es la visión misma de la vida humana, a caballo entre lo natural y lo tecnológico (Cózar, 2019). Las ambivalencias son inevitables...

Claro que el trasfondo económico es decisivo: la financiarización de la economía es el paso lógico y necesario para mantener las tasas de ganancia en un mundo globalizado, de modo que el valor de aquellos fondos es unas once veces mayor que la llamada economía real y que el endeudamiento generalizado es la vía elegida para producir nuevas plusvalías, una vez agotados otros nichos de extracción. Esto también es parte del Antropoceno, no se olvide, en el sentido amplio aquí utilizado: la depredación -ahora exponencial- es del todo coherente con la raíz última del modelo capitalista según Marx, es decir, con la generación insaciable de valor mercantil y monetario, basado en la descualificación de personas, objetos y actividades para convertirlos en abstracciones intercambiables (Jappe, 2016), lo que incluye también a la naturaleza como un todo. Y es que si uno deja de dar pedales, la bicicleta se cae antes o después. De ahí que sea tan difícil alcanzar el llamado estado estacionario de la economía y más aún practicar el decrecimiento, pues ello niega la entraña misma del sistema y supondría incluso su deslegitimación, por cuanto rompería con el mito central del crecimiento indefinido y la supuesta redistribución. Así pues, las reformas de cualquier índole dentro del modelo serían muy necesarias, pero no parece que suficientes. Planteemos una pregunta sencilla a modo de contraste: si se consiguiese producir la suficiente energía renovable ¿no se seguiría empleando para los mismos fines productivistas?

\subsection{El colapso probable}

Para muchos, mentar este vocablo es propio de espíritus fatalistas o incluso resentidos, pero lo cierto es que se abre paso de manera tozuda como algo probable, a la vista de los datos y las prospectivas racionales no acomodaticias. Las resistencias psicológicas y político-económicas son tremendas, en el seno de una sociedad sonámbula, consumista y acelerada, ocupada en mil problemas secundarios y dispuesta a confiar en el milagro tecnológico de última hora. Pero la evidencia, entre otras, de un cambio climático agravado no deja mucho margen al optimismo. 
Recordemos a este respecto que desde finales de los años treinta del siglo XX se conocía el riesgo de calentamiento, con investigaciones científicas cada vez más sólidas y documentadas en las décadas siguientes, sin que se haya hecho nada realmente eficaz para afrontarlo, a pesar de constar su carácter no lineal y retroalimentado, abrupto y ligado a umbrales críticos que disparan los efectos, con una envergadura y amplitud extraordinarias en sus implicaciones (Escrivá, 2018). Ni siquiera los conocidos y preocupantes informes de la comunidad científica internacional (IPCC) que lo investiga desde 1988 sirven para que se tomen medidas de alcance, por más que este siglo concentre 17 de los 18 años más cálidos registrados. Que los fenómenos naturales extremos se hayan multiplicado por cuatro desde los años 70 , que las partículas de carbono por millón de moléculas (ppm) se acerquen hoy a las 410 y para 2050 se prevea que lleguen a las 450, con lo que la temperatura media del planeta sería dos grados más alta que la de la era industrial (FAO, II: 16), no merece la atención debida. Huelga decir que traspasar este umbral -y en esa dirección vamos- generaría catástrofes inimaginables que preparan el colapso.

Tampoco parece contar lo bastante que la deforestación desde 1990 haya arrasado unos 130 millones de hectáreas (el equivalente a la superficie de Sudáfrica) y que cada minuto se pierdan otras 36 (FAO, I: 17-19), con lo que decae uno de los dispositivos fundamentales de estabilización. Por no hablar de las serias incertidumbres alimentarias para una población en aumento, lo que ya es objeto de especulación financiera (en particular en la bolsa de Chicago) con las denominadas compras a futuro de cosechas. Hará falta aumentar un 50\% el agua dedicado a producir alimentos y un $400 \%$ más para la producción de manufacturas en las próximas décadas; mientras que se calcula un "estrés hídrico" de uno u otro tipo para la mitad de la población mundial en el año 2030, lo que afectará nada menos que a los dos tercios en 2050 (FAO, IV: 7 y 41). Estos ejemplos relevantes muestran las tendencias socio-ecológicas de base, sobre el muro de la asimetría de responsabilidades, la injusticia y la desigualdad, dado que en términos redondos el $20 \%$ más rico consume el $80 \%$ de los recursos, a la vez que produce el $80 \%$ de los desechos. A nadie se le oculta que los perjuicios son generales, pero se reparten de manera harto desigual, mucho más dolorosos para los pobres de la tierra y especialmente para mujeres y niños por su evidente vulnerabilidad.

Es inevitable mencionar también la pérdida galopante de biodiversidad que trastoca casi todos los ecosistemas, el deshielo masivo (Groenlandia pierde cada año el equivalente a 110 millones de piscinas olímpicas), la inexorable 
subida del nivel del mar que afectará a cientos de millones de personas que viven en zonas costeras, la acidificación de los océanos que ha aumentado un $30 \%$ y cuyas corrientes cambian, amén de una sobreexplotación ubicua, muy grave en la pesca, la ganadería y los monocultivos. Hagamos una breve incursión en un tema con relaciones varias: si el $80 \%$ de la superficie cultivable se dedica a producir alimento para el ganado (que es parte principal de los 75.000 millones de seres vivos sacrificados al año por el hombre) y en el resto priman los cultivos más rentables (p. ej. los "biocombustibles") frente a los más nutritivos o necesarios, algo extremadamente nocivo ocurre. El resultado es un derroche combinado de agua que se refleja bien con otros ejemplos significativos: hay transferencia global de agua ("agua virtual" se llama) cada año del Sur al Norte en forma de alimentos, carne y manufacturas poco elaboradas; a la par que producir un kilo de carne de vacuno consume 15.000 litros de agua, si se incluyen todos los conceptos (riego de pastos, estabulación, manufactura, transporte...); claro que es mucho peor dedicar 7200 millones de litros diarios a regar los campos de golf de EE. UU. (Espinosa, 2011). El expolio, la desmesura y el derroche hablan por sí mismos.

En resumen, van a escasear el agua y los alimentos, a la par que se desequilibran los ciclos geobiofísicos y químicos esenciales para la vida, pero la lógica del negocio por un lado y la del despilfarro por otro siguen mandando. Y dentro del sistema económico se discute, en el mejor de los casos, si tomar algunas tímidas medidas que penalicen a los combustibles fósiles o cómo ser más eficientes para seguir igual. Al margen de la buena intención de algunos y de la urgentísima necesidad de dar pasos, como en la fiscalidad de los asuntos ambientales, parece imposible aceptar que la situación ha llegado a un punto en que se requiere un cambio radical de modelo, pues toda la economía política está en cuestión (Arias Domínguez, 2018). Bienvenidas sean las mejoras parciales y las reformas, pero desde la conciencia trágica de que no bastan, incluidos los posibles y necesarios hallazgos tecnológicos. Digamos de modo gráfico que nunca habrá agua digital y que la salvaguarda de la vida demanda un giro paradigmático, como muestra el hecho de que nueve millones de personas mueren al año por diversos tipos de contaminación (el $16 \%$ del total de muertes), más que cualquier otra enfermedad, ocasionando un gasto del $6.2 \%$ del PIB mundial (Ecoportal.net 8-11-2017), aunque los problemas sanitarios que se adivinan no han hecho sino comenzar. Pero es que algo tan elemental como proteger la salud no parece prioritario ante la cuenta de resultados, máxime cuando se diluyen las responsabilidades en un mar de causas y efectos, escalas y factores, de donde surgen esos efectos 
colaterales. Nadie tiene la culpa, salvo en casos muy acotados, luego ¿a quién pedir cuentas?

Desde el punto de vista de las migraciones que tales hechos ocasionarán, hay que decir que se prevé un movimiento forzoso de nada menos que unos mil millones de personas en los próximos cincuenta años (El País Extra Cambio Climático, 4-1-2015), con los conflictos que ello traerá consigo. Si las migraciones actuales ya disparan la xenofobia y la adopción de medidas represivas de toda clase, no es difícil suponer una futura explosión de violencia asentada en la mezcla de miedo, ignorancia, manipulación y escasez. De hecho, el catálogo de guerras climáticas de alta o baja intensidad ya es más que notable, en interacción con la pobreza y el creciente número de estados fallidos (Welzer, 2010: 180ss, 118s y 127). El caos geopolítico y la feudalización de muchos territorios avanza a pasos agigantados, entreverado a menudo con las cuestiones ecológicas, mientras que sigue faltando una cobertura legal apropiada para los refugiados ambientales y se construyen más y más muros. Las estadísticas recientes no dejan lugar a dudas: los choques armados informales y los desplazados han aumentado un $125 \%$ desde 2010 y el $40 \%$ de las guerras civiles están relacionadas con la lucha por recursos menguantes (FAO, I: 89 y 92). Los enfrentamientos seguirán creciendo por razones obvias y cada cual tomará sus medidas. Por otro lado ¿qué cabe imaginar que ocurrirá cuando en 2050 los dos tercios de la población mundial vivan en megalópolis en muchos casos sin servicios básicos ni orden inclusivo, como adelanta el dato de que 850 millones de personas ya viven en suburbios y que hay unos 750 millones de migrantes internos (FAO, I: 79ss)? ¿Cuánto se multiplicarán los guetos sociales o los choques por conseguir agua, como ya sucede por ejemplo en las grandes ciudades de la India?

Las limpiezas étnicas y los genocidios son la prueba extrema de las reacciones que ocasiona la sensación de un riesgo vital y permanente: los cambios socio-psicológicos son rápidos cuando los episodios traumáticos desbordan los valores anteriores, tanto más cuanto que el cambio climático y sus efectos no son previsibles ni tienen una clara resolución (Welzer, 2010: 89, 232, 237 s, 278). La violencia, en fin, se convierte en la respuesta lógica y al parecer inevitable ante semejantes peligros e incertidumbres, de modo que muchos ciudadanos desean soluciones drásticas, a menudo totalitarias, como ya se ve en el horizonte. La inversión de los principios éticos y democráticos es de tal calibre que podría pensarse en un nuevo eslogan que enuncie "Fascismo o barbarie" (Bolaño, 2009: 27), concebido para afrontar, paradójicamente, el caos. Es decir, una nueva vuelta de tuerca en esta realidad cada vez más 
alienada, desde la impresión de que el mundo está del revés y avanza hacia el precipicio, atrapado dentro de enmarañadas luchas geopolíticas, por los recursos, religiosas, de clases...

Lo que no es una impresión sino una certeza es la denominada securitización de los problemas ambientales, con el cambio climático a la cabeza. Los informes de inteligencia y defensa a escala mundial muestran la militarización de estos temas, aunque lo más desolador sea que los grandes países y corporaciones sólo quieren asegurar sus posiciones, no incidir sobre las causas de la situación. La seguridad nacional y los privilegios económicos se dan la mano una vez más ante las grandes amenazas, generando a su vez más nichos de negocio (ejércitos privados, capitalismo verde, geoingeniería, comercio de armas, seguros, etc.) en la gestión de las mismas (Buxton y Hayes, 2017). El escenario que se prepara ahonda la división entre una minoría de ganadores y la gran mayoría de perdedores, si bien los ecosistemas se deterioran para todos los seres vivos. Y la manera que algunos tienen de llevar a cabo esos planes de supervivencia y aprovechamiento se articula en torno al ecofascismo (como ya se viene discutiendo desde la famosa polémica entre M. Bockchin y R. Bahro), pero con la salvedad de que ahora se plantea abiertamente la posible relación entre el futuro colapso y nuevos holocaustos (Snyder, 2015). No es posible dudar siquiera del inmenso peligro que acecha a la humanidad, a la vista de los precedentes y sin necesidad de exagerar las cosas: dadas ciertas condiciones, lo impensable se abre camino.

Quizá se entienda mejor por qué es pertinente hablar de un colapso generalizado, aunque sus variantes sean muchas y nadie pueda adivinar qué ocurrirá con exactitud. Es cierto que el capitalismo lo impregna todo con un aroma seductor a la par que represor y que la población es en buena medida tan cómplice como deudora de ello por razones complejas (Espinosa, 2015), pero hay cosas que no pueden ocultarse indefinidamente y el choque con la realidad será entonces aún más cruel. Al igual que el cambio climático, que sirve de punta de lanza, cabe suponer que el hipotético colapso tendrá una distribución y unos efectos y plazos desiguales, con lo que a la postre se refuerza el pensamiento mágico del tipo "alguna solución de última hora habrá" o "a mí no me va a tocar o por lo menos no tanto", etc. Cómo imaginar el desmoronamiento de todo un mundo y su forma de vida, sin paralizarse...

Ha llegado el momento de introducir otros elementos específicos e intentar definir el concepto de colapso: al cambio climático y sus secuelas se añade de forma determinante la escasez previsible de todo tipo de recursos, 
lo que atañe a combustibles fósiles y minerales en general, según los datos y las prospectivas actuales. No es que la producción de petróleo haya alcanzado probablemente ya su tope, lo que afecta a sus incontables derivados, sino que hay motivos para hablar de un peak everything, si se incluyen las otras carencias mencionadas (Heinberg, 2007). La escasez de bastantes componentes claves de la civilización actual llama a la puerta con insistencia, por más que las cifras concretas oscilen, con el añadido de que la mayor parte de las reservas ya localizadas deberían no explotarse para limitar los GEI. En todo caso, las energías renovables tienen una capacidad limitada de sustitución, bien sea por su volumen insuficiente y porque la transición es muy cara, o por el gasto que exigen de electricidad, o por la dificultad para almacenarlas y transportarlas...; además, la tasa de retorno (TRE) o saldo neto de energía entre lo gastado y lo obtenido baja sin parar; y la conjunción de problemas apunta a una quiebra general del sistema, avalada por experiencias históricas anteriores y por el análisis estructural del presente en términos de déficit energético y carestía (Fernández Durán y González Reyes, 2015). Sí, el planeta es definitivamente finito a todos los efectos y la brillante ingeniería humana no da abasto para compensarlo.

El colapso se define, pues, como la crisis sistémica, irreversible y traumática, de las estructuras institucionales, económicas y sociales que satisfacen las necesidades actuales de una colectividad, que al cabo será mundial, con los consecuentes conflictos y revueltas. Como ha resumido Carlos Taibo (2016: 24-38), se trata de una pérdida de complejidad en todos los ámbitos que incluiría la desarticulación de las relaciones de diversa índole y la fragmentación de grupos y territorios, el fracaso de las administraciones centrales, la dificultad para imponer la ley y otras formas de orden y cohesión, el descenso brusco de la población, la ruptura de las comunicaciones y del transporte, y en definitiva la quiebra de los flujos de materia, energía e información. Puede ser un proceso rápido o lento, cíclico o lineal, más o menos visible como en los estados fallidos o en la ciudad de Detroit, presente en el declive de unos servicios públicos saturados o en vastas zonas despobladas..., pero acabarán por ponerse en jaque las cadenas de producción y abastecimiento, la burocracia y la seguridad, los servicios de salud, agua y electricidad, etc. Dicho en una fórmula: el caos creciente que ya sufren en muchos lugares del planeta, donde el colapso es cotidiano y viene de antiguo, así como la extensión brutal del sálvese quien pueda.

Se discute sobre una posible secuencia de etapas con efectos distintos, por ejemplo si tendrá antes un carácter económico o ecológico, donde en 
caso de darse lo primero se salvaría parte de la biosfera y si lo segundo se desencadenaría un declive definitivo y sin posibilidad de regeneración natural. También se aventura que la crisis financiera y de deuda pudiera ser el inicio, seguida por la comercial y después la política, hasta llegar a descomponer finalmente la sociedad. Y no faltan indicios para ver en los últimos años algunos preocupantes avances de ello, en términos de recesión, proteccionismo, nacional-populismos, pérdida de la multilateralidad internacional, guerra fría rediviva, anomia, dogmatismos sectarios... El retrato del precolapso y del postcolapso sólo es tentativo y aproximado, claro está, pero no es difícil suponer peligros superlativos para el ejercicio de las libertades públicas o imaginar ciudades semi-abandonadas, así como la probable vuelta a una vida sencilla en el campo y tal vez a comunidades locales autogestionarias (Taibo, 2016: 114 y 120ss, 153-167). Lo más verosímil es la llegada de una austeridad generalizada, ya se trate de algo impuesto por la fuerza de las circunstancias o acaso elegido y mejor gobernado. El problema entonces sería la ignorancia e incompetencia de gran parte de la población para afrontar otra forma de vida material en la que los aparatos no tengan protagonismo y falten los suministros de casi todo.

Sea como fuere, importa destacar en sentido conceptual que la gran complejidad (retroacciones, diferenciación e integración simultáneas) del mundo presente comporta a la vez una mayor vulnerabilidad, que las propiedades emergentes del todo y de las relaciones de las partes entre sí conforman por un lado la densidad y riqueza de una autoorganización creativa del sistema y, por otro, la aparición de desórdenes y derivas impredecibles e ingobernables (De Landa, 2016: 15,21). A la mayor variedad de planos y aspectos, de vínculos y facetas, le corresponde una mayor interdependencia y fragilidad. Sobre todo, cuando es probable que los sistemas abiertos (socio-naturales) de los que aquí se trata sufran una especie de cortocircuitos o bloqueos y no puedan retroalimentarse, o tal vez carezcan de la suficiente energía para producir las disipaciones (según la ya clásica expresión de Prigogine) que permiten su reorganización en diferentes niveles de complejidad. Sin fines y sin medios, no es que se rompa sólo la cadena de valor, es que cambia drásticamente la idea de valor. Se puede morir de éxito, en efecto, cuando no hay una mínima previsión correctora de las malas inercias, siquiera hasta donde la contingencia histórica lo permita. La entropía gana siempre, cierto, pero que ocurra así sería una noticia pésima. 


\subsection{Sobre ciertas lineas de fuerza en el debate}

No se trata de ser más o menos pesimista u optimista ni sólo de abrir un debate ideológico, sino de plantar cara a un riesgo grave y cierto: el Antropoceno puede implicar algún tipo de colapso porque la colonización humana del planeta lo ha desequilibrado en términos de conservación y regeneración de bienes y recursos, amén de las grandes injusticias y desigualdades anexas, lo que se traduce en un inmenso sufrimiento físico y psíquico de los seres humanos, pero también de otras especies. No se piense sólo en bancarrotas, falta de empleo, ausencia de las viejas comodidades (para quienes las tienen), etc., sino en hechos mucho más radicales, como que el hambre y la sed, la angustia, la incertidumbre y la desprotección... generan profundas depresiones, hasta el punto de que para muchos la vida no merezca la pena o deba ser defendida mediante la violencia. Las crisis de toda clase van mucho más allá que la omnipresente macroeconomía, lo cual, a su vez, tiene que enmarcarse en un presente histórico bastante más complejo.

Cabe afirmar, recapitulando, que hay una convergencia de al menos tres procesos de fondo que atacan la vida humana: la policrisis socio-ambiental que aquí se intenta condensar, con sus múltiples ramificaciones, entendida como la vertiente extensional del conjunto; la dinámica automatizada e insaciable de un sistema de producción y consumo basado en la lógica del valor que convierte a todo ente en algo abstracto y cuantificable, transformado en mercancía y dinero (Jappe, 2016), lo que supone el aspecto intensional ahora acelerado; y la implementación de tecnologías convergentes (NBIC, inteligencia artificial, robotización, etc.) que apuntan a una realidad artificial cada vez más independiente y ligada al control de las personas y a la eventual creación de posthumanos (Harari, 2016: 59, 304), lo que encarna el aspecto transversal que cataliza a los dos anteriores. El resultado es que los seres humanos y en buena medida muchas otras expresiones de la vida resultan prescindibles, una vez se los ha despojado de contenido y valor inmanente, concreto e irreductible, o de su capacidad de actuar y decidir, de crear bienes y relaciones, en fin, de ser sujetos y no objetos. Se trata de algo radicalmente inédito en la historia y que rebasa las alienaciones habituales: es el puro nihilismo de la fungibilidad absoluta.

Veamos un poco más de cerca este curso de las cosas que ya ha comenzado, aunque no tenga pleno desarrollo: la escasez de recursos y el cambio climático matarán gradualmente, de manera natural, a gran parte de la población, sin excesivo disgusto o conmoción del resto, que así verá aumentar 
sus posibilidades de sobrevivir; en segundo lugar, al agotarse la producción ordinaria de valor en la economía real, se recurre a la especulación financiera globalizada como vía lógica de expansión compensadora, donde los humanos ni siquiera son variables a tener en cuenta dentro del flujo de capitales; y, por último, la automatización inteligente hace innecesario contar con esos seres finitos mucho más falibles, ya sea para el trabajo, la política o la milicia, ganando el sistema en eficacia y rendimiento. Repárese además en que esos tres procesos están conectados y son no lineales, luego la combinatoria es imprevisible e ingobernable. El paradójico balance final es que el Antropoceno puede ser un mundo en el que el Anthropos no tenga protagonismo alguno.

La enorme ironía de todo ello es que sólo un colapso de la civilización pondría fin a esas dinámicas, en tanto que resultado de la exacerbación de las contradicciones internas y de la falta de medidas de contención ante las presiones externas. El aparente círculo virtuoso que algunos podrían ver en esa convergencia, se convertiría así en vicioso y trágico, si es que no lo era ya. A la violencia estructural que ya se arrastra como efecto de la explotación y el dominio (correlativos del ser humano y de la naturaleza), se sumaría una violencia simbólica -que ya se ha puesto en marcha-contra los otros (migrantes, extraños, competidores de cualquier tipo, etc.) y otra violencia estratégica generalizada como herramienta para afrontar el caos, aun con diferente gradación táctica según los casos. Cambiar libertad por seguridad es algo frecuente en la historia, así como mantener unos "mercados de la violencia" muy rentables cuando nada es estable (G. Elwert en Walzer, 2010: 163ss). No es fácil romper la cadena cuyos eslabones son la escasez, conflictos medioambientales, catástrofes, miedo, migraciones, etc.; más aún sobre la base de que la pérdida de biodiversidad es letal para combatir el cambio climático y la pobreza, promover la igualdad de género, obtener agua y cuidados sanitarios, seguridad alimentaria y desarrollo sostenible (FAO, III: 9). Por supuesto que nadie sabe qué ocurrirá, pero el suicidio del sistema global humano no deja apenas opciones abiertas.

La tragedia es patente: a día de hoy no hay masa crítica para desencadenar un cambio profundo, pero incluso si se quisiera transformar estructuras y modelos a gran escala, hay demasiadas cosas que hacer y muy poco tiempo para llevarlo a cabo. No se puede vender esperanza a precio de saldo y hay que decir la verdad (provisional) de lo que se ve, basándose en las pruebas disponibles. Lo cual, por cierto, conlleva un fuerte impulso de los análisis desde la ecología política, es decir, sobre las múltiples relaciones de poder vinculadas con estas cuestiones, tal como han mostrado Dietz, Barca, Ojeda 
o Roa (Arias Henao, 2017). Sin embargo, también es cierto que no queda otro remedio que defender y profundizar en la democracia como la mejor herramienta para frenar a unas élites acaparadoras e implacables, amén de establecer redes ciudadanas de participación directa, ayuda y cooperación. Al consabido mensaje en favor de la descarbonización y las renovables, el menor consumo y la pedagogía ecológico-social, la eficiencia frente al derroche, una fiscalidad verde ambiciosa, la socialización del crédito y de los servicios públicos básicos, el reciclaje masivo (ahora sólo es del 9\%) y las transformaciones industriales y agropecuarios de calado..., hay que sumar la redistribución equitativa de bienes ambientales y el logro de una conciencia profunda de lo que podría llamarse el bien común ecológico. La bioética global proporciona principios normativos y valores para ello (Ten Have, 2016: cap. 12), a partir del reconocimiento de la vulnerabilidad humana, la solidaridad e igualdad como guías, la responsabilidad social, o la protección de la biosfera y la biodiversidad, así como de las próximas generaciones. Se sabe lo que hay que hacer...

No parece suficiente, pero - por dar unos ejemplos relevantes- la conocida proclama que afirma Decrecimiento o barbarie (P. Ariés) resulta imprescindible en primera instancia, al igual que lo son las redes de resistencia y en favor de la justicia climática (denominadas por N. Klein Blockadia) o las recientes protestas que jóvenes estudiantes realizan para defender su futuro. En definitiva, acumular fuerzas y marcarse objetivos intermedios, sin dejar de ser combativos incluso en la derrota, pues hay que asumir el duelo ante tantas esperanzas pérdidas y recordar además que "Hay colapsos y colapsos; hay genocidios y genocidios; hay diversas formas de fracasar" (Riechmann 2015: 253 y 250). Desgraciadamente, así de mal parecen estar las cosas, aun a riesgo de recibir la acusación habitual de catastrofismo. Lejos de la inacción, una vez más hay que actuar como si todavía fuera posible la regeneración global y al menos aminorar los golpes: reducir en parte el aumento de la temperatura global ya tendría efectos apreciables y de ahí a mejor en todo. Aquí es obligado practicar un firme posibilismo, aun contra todo pronóstico, como demuestran los efectos constatados al hacer inversiones en desarrollo sostenible y protección integral (semillas, educación, vacunas, seguros, créditos...) para afrontar el deterioro generalizado (FAO, I: 75ss). Y es que a veces se hace lo debido.

La lucha por influir más y mejor en la agenda pública es el primer paso, a la vista de la negación o manipulación y, en todo caso, suavización de los problemas. Los sesgos son obvios en la comunicación y evaluación del tema, además de eludir los fallos sistémicos y trasladar los eventuales cambios a la esfera 
particular. Por otro lado, el rechazo psicológico de la mayoría ante el horror es comprensible, las incertidumbres y dudas infladas por grupos de interés son eficaces, la ceguera ante la no inmediatez (espacial y temporal) de los procesos es clara, la ignorancia e indiferencia deliberadas tienen peso, la presión de otras urgencias que resultan más cercanas cuenta mucho, etc., de forma que incluso la asumpción teórica no da paso a la toma de medidas coherentes. Sabemos sin saber de verdad, sin interiorizar las consecuencias, y hay una disposición a reaccionar siempre que ello no implique asumir grandes costes y renuncias. Al fin y al cabo, se dice, esto es cosa de todos y de nadie en concreto, la aportación personal es mínima frente al gran conjunto de las estructuras implicadas y poco puede hacer cada uno; o bien se imponen la frustración y el pesimismo de modo paralizante, o tal vez se cree que siempre habrá otros que den los pasos pertinentes... No faltan los mecanismos de evasión, como se ve.

Pero conviene reiterar que hay grados muy diferentes de responsabilidad y que la negligencia criminal, cuando no la acción directa y los engaños que matan, no son atribuibles en primer lugar a la masa de particulares. En todo caso, se ha dicho con razón que conviene mostrar las salidas posibles y las ventajas prácticas que las acompañan, ir más allá del enfoque científico y sólo ambiental para adentrarse en las implicaciones sociales y políticas, de manera que al final se pongan en marcha mecanismos colectivos de acción responsable, a partir de los cuales se aprenda sobre la marcha cómo seguir adelante (Heras, 2012). Claro que el problema consiste en dónde trazar las fronteras, de suyo fluidas, para llamar a las cosas por su nombre sin desmotivar a nadie. En la actual economía de la atención se pugna por atraerla con recursos muy dispares y no es nada fácil abrirse paso entre tantas mentiras y ofrecer buenas informaciones. La tarea titánica consiste en enfrentarse sin cesar a los círculos viciosos entre Antropoceno, cambio climático, pérdida de biodiversidad y colapso con una propuesta que sea viable $-\mathrm{y}$ sobre todo poderosa- de un nuevo contrato ecosocial o, si se prefiere, de una suerte de patriotismo republicano planetario. $Y$ ésa es la lucha permanente... Aún queda algún margen de contingencia frente al destino y debe recordarse que en los sistemas complejos también caben las desviaciones o bifurcaciones favorables, si se saben aprovechar.

\section{BibliografíA}

Arias Domínguez, A. (2018), La economía política del desastre. Efectos de la crisis ecológica global, Madrid, Libros de la Catarata. 
Arias Henao, J. (2017). “La nueva economía verde y la vieja mercantilización de la naturaleza”, Ecología política, 53.

Arias Maldonado, M. (2018). Antropoceno: la politica en la era bumana, Madrid, Taurus.

AystarÁn, I. (2009). “La segunda revolución copernicana de Kant a Kuhn: el paradigma de la sostenibilidad y la ética del cambio climático”, Daimon n. ${ }^{\circ} 47$ (65-82) 2009.

Bolaño, R., (2009). Una novelita lumpen, Barcelona, Anagrama.

Buxton, N. y Hayes, B. (2017). Cambio climático, S. A., Madrid, Fuhem.

Cano Ramírez, O. E. (2017). “Capitaloceno y adaptación elitista”, Ecología politica, 53

Cózar De, J. M. (2019). El Antropoceno. Tecnología, naturaleza y condición bumana, Madrid, Libros de la Catarata.

Coetzee, J. M. (2007). Diario de un mal año, Barcelona, Mondadori.

Crutzen, P. J. y Stoermer, E. F. (2000). “The Anthropocene”, Global Change Newsletter, 41, 17.

EsCRIVÁ, A. (2018). Aún no es tarde. Claves para entender y frenar el cambio climático, Valencia, PUV.

EspinosA, L. (2007). “La vida en la eco-bio-tecno-noos-fera”, Logos 40, pp. 47-60.

Espinosa, L. (2011). "Reflexiones sobre el agua, un espejo del presente”, Dilemata. net $\mathrm{n} .^{\circ} 6$.

Espinosa, L. (2014). “Realidades sociales dislocadas, estilos de vida precarios”, Mundo Nuevo VI, 14, pp. 137-172.

FAO (2018). Vol. I: Los grandes desafíos; Vol. II: El cambio climático; Vol. III: La biodiversidad; Vol. IV: El agua. Publicado con El Pais, Madrid.

Fernández Durán, R. y González Reyes, L. (2018) (reed.) La espiral de la energía, Madrid, Libros en Acción y Baladre.

Hamilton, A., et al. (2015). The Anthropocene and the Global Environmental Crisis, New York, Routledge.

Harari, Y. N. (2016). Homo Deus. Breve historia del mañana, Madrid, Debate.

Heinberg, R. (2007). Peak Everything. Waking up to the Century of declines, New Publishers Publications.

Heras Hernández, F. (2012). "Negacionistas, refractarios e inconsecuentes. El difícil reto de reconocer el cambio climático", Ecoportal.

Herrero, A. (2017). "Navegando por los turbulentos tiempos del Antropoceno", Ecología politica 53.

Landa De, M. (2017). Mil años de historia no lineal, Barcelona, Gedisa, (2. a ed.).

Moore, J. (2015). Anthropocene or Capitalocene? Nature, History and the Crisis of Capitalism, Oakland, PM Press.

Moreno, C., Speich, D. y Fuhr, L. (2016). La métricadel carbono ¿El $\mathrm{CO}_{2}$ como medida de todas las cosas?, Fundación Heinrich Böll, Ciudad de México. 
Naím, M. (2013). El fin del poder, Madrid, Debate.

Oreskes, N. y Conway, E. M. (2010). Merchants of Doubt, New York, Bloomsbury Publishers.

Riechmann, J. (2015). Autoconstrucción, Madrid, Libros de la Catarata.

Riemen, R. (2018). Para combatir esta era, Madrid, Taurus.

Rosanvallon, P. (2012). La sociedad de los iguales, Barcelona, RBA.

Rull, V. (2018). El Antropoceno, Madrid, csic/Libros de la Catarata.

SNYDER, T. (2015). Black Earth. The Holocaust as History and Warning, London, The Bodley Head.

SPIER, F. (2011). El lugar del hombre en el cosmos, Barcelona, Crítica.

TAibo, C. (2016). Colapso: capitalismo terminal, transición ecológica, ecofascismo, Madrid, Libros de la Catarata. 
